DOI: $10.34220 /$ issn.2222-7962/2020.3/9

УДК $630 * 176.630 * 18$

ПРОБЛЕМА ВЫЯВЛЕНИЯ И НАЗНАЧЕНИЯ В РУБКУ АВАРИЙНЫХ ДЕРЕВЬЕВ НА ТЕРРИТОРИИ ГОСЛЕСФОНДА

\author{
доктор сельскохозяйственных наук, доцент В.В. Царалунга \\ кандидат биологических наук А.В. Царалунга \\ магистрант А.В. Короткая
}

ФГБОУ ВО «Воронежский государственный лесотехнический университет имени Г.Ф. Морозова»,

г. Воронеж, Российская Федерация

В рамках обследования насаждений вдоль Большой Воронежской экологической тропы проведены исследования по определению качественных и количественных характеристик патологий на деревьях, которые не учитываются в инструктивных документах, но фактически определяют эти деревья как аварийные. Кроме стволовых гнилей и опасного наклона ствола, рекомендованных инструкциями, учитывались деревья с комлевыми дуплами, раковыми опухолями на стволе, расщеплением ствола и усохшими скелетными ветвями. Собранный материал и его анализ показали, что в случае учета деревьев с такими патологиями количество деревьев, относимых к категории аварийных, может возрасти на $62 \%$. Среди дополнительных патологий лидируют комлевые дупла. Указано, что кроме данных патологий, характерных для дубравных древостоев, есть еще ряд фатальных для деревьев патологий, встречающихся в других типах насаждений. Сделан вывод, что современная методика выделения аварийных деревьев несовершенна, поскольку не учитывает значительное количество древесных патологий, которые увеличивают вероятность облома или вывала дерева, что однозначно делает такие деревья аварийно опасными.

Ключевые слова: правила санитарной безопасности в лесах, аварийные деревья, стволовая гниль, раковая опухоль, комлевое дупло, расщепление ствола, скелетные ветви

\title{
THE PROBLEM TO IDENTIFY AND ASSIGN THE LOGGING OF EMERGENCY TREES IN THE TERRITORY OF STATE FOREST FUND
}

\author{
DSc (Agriculture), Associate Professor V.V. Tsaralunga \\ $\mathrm{PhD}$ (Biology) A.V. Tsaralunga \\ Master's degree student A.V. Korotkaya \\ FSBEI HE "Voronezh State University of Forestry and Technologies named after G.F. Morozov", \\ Voronezh, Russian Federation
}

\begin{abstract}
The studies to determine the qualitative and quantitative characteristics of pathologies on trees have carried out as a part of a survey of plantations along the Big Voronezh ecological trail. These characteristics are not taken into account in the guidance documents, but in fact they define these trees as emergency ones. In addition to stem rot and dangerous trunk slope, recommended by the instructions, trees with butt hollows, cancerous tumors on the trunk, splitting of the trunk and shriveled skeletal branches were taken into account. The collected material and its analysis showed that (in case of accounting for trees with such pathologies) the number of trees classified as emergency can increase by $62 \%$. Among additional pathologies, butt hollows take the leading position. It is indicated that there is a number of pathologies fatal for trees found in other types of plantations (in addition to these pathologies characteristic of oak stands). It is concluded that the modern technique for identifying emergency trees is not perfect, since it does not take
\end{abstract}




\section{Природопользование}

into account a significant number of tree pathologies that increase the likelihood of tree breaking off or falling out, which definitely makes such trees extremely dangerous.

Keywords: sanitary safety rules in forests, emergency trees, stem rot, cancerous tumor, butt hollow, split trunk, skeletal branches

\section{Введение}

По мере увеличивающейся синантропизации отечественных лесов, особенно пригородных и в густонаселенных регионах, обостряется проблема с падением деревьев на дороги, транспорт, коммуникации, строения и т. д. И если в городских условиях проблема аварийных деревьев существует давно и относительно успешно решается $[1,3,5,9,11]$, то на территории гослесфонда отнесение деревьев к категории аварийных и оформление их отвода в рубку имеет определенные сложности, связанные, в основном, с несовершенством методики оценки состояния дерева и излишней бюрократизацией оформления документов. В действующих правилах санитарной безопасности [4], руководствах по планированию и проведению лесопатологического обследования [8], лесопатологического мониторинга [7] и санитарно-оздоровительных мероприятий [6] приводятся только два (!) признака, по которым дерево может считаться аварийным. Это наличие гнили и (или) опасный наклон. Кроме того что это крайне ограниченный перечень фатальных для дерева патологий, способных сделать дерево аварийным, он не дифференцирован по характеру и степени развитости данных патологий.

Исходя из этого, мы задались целью (в рамках государственных контрактов № 8-10 от 18 июня 2019 года между департаментом природных ресурсов и экологии Воронежской области и Воронежским государственным лесотехническим университетом имени Г.Ф Морозова по выявлению аварийных деревьев вдоль Большой Воронежской экологической тропы) провести исследования по определению качественных и количественных характеристик патологий на деревьях, которые не учитываются в инструктивных документах, но фактически определяют эти деревья аварийными $[2,10]$.

\section{Материалы и методы}

Исследования проводились в июне-августе 2019 года на территории Правобережного участко- вого лесничества Учебно-опытного лесхоза Воронежского государственного университета имени Г.Ф. Морозова. Насаждения вдоль экологической тропы представлены, в основном, порослевыми дубравами приспевающего и спелого возраста с большой примесью (до 5 единиц) ясеня обыкновенного, клена полевого и липы мелколистной.

Обследовались деревья в полосе 100 м (по 50 м с обеих сторон от «тропы») на протяжении 7,28 км в 15 кварталах и 58 выделах. Всего было осмотрено 26800 деревьев с диаметром на 1,3 м более 12 см. Общая площадь обследованных насаждений составила 72,8 га (табл. 1).

Выявленное аварийное дерево обмерялось (диаметр, высота), определялась его порода, описывалась патология, фиксировались координаты (широта и долгота до секунды), и ствол помечался масляной краской. Деревья, которые не подпадали под категорию аварийных по действующим нормативам, но имели патологии, которые, в определенных условиях, могут стать фатальными, просто фиксировались по виду обнаруженной патологии.

Основываясь на многолетнем опыте исследований древесных патологий $[12,13]$, мы в качестве таких внешних признаков взяли наиболее распространенные: комлевое дупло, раковые опухоли на стволе, раздвоение ствола и усохшие толстые скелетные ветви (рис. 1). Фатальность для дерева каждого из этих внешних признаков не одинакова и зависит как от степени развитости патологии, так и от индивидуальной жизнеспособности дерева. Однако потенциально любая из этих патологий многократно увеличивает риск вывала или облома ствола, а также его расщепления или облома крупной ветви.

Каждая из дополнительных патологий учитывалась только в максимальной степени своего развития, когда угроза механического разрушения дерева или его части очевидна. Так, комлевое дупло учитывалось, когда оно не имело перспективы зарасти, поскольку достигало размера, соизмеримо- 


\section{Природопользование}

го с диаметром ствола, и имело полностью выгнившие внутренности (рис. 1, а). Раковые опухоли учитывались либо окаймляющие, либо трещиноватые, имеющие протяженность более диаметра ствола в месте локализации (рис. 1, б), Из деревьев с раздвоением ствола учитывались только те, в ко- торых имеются или наметились трещины в месте раздвоения (рис. 1, в). И как аварийные фиксировались деревья с усохшими толстыми скелетными ветвями (соизмеримыми с диаметром ствола в месте крепления) и обращенными в сторону «тропы» (рис. 1, г).

Таблица 1

Участки, обследованные в процессе выявления аварийных деревьев вдоль экологической тропы в Правобережном участковом лесничестве Учебно-опытного лесхоза ВГЛТУ

\begin{tabular}{|c|c|c|c|c|c|}
\hline Квартал & Выдел & $\begin{array}{c}\text { Площадь, } \\
\text { га }\end{array}$ & Квартал & Выдел & $\begin{array}{c}\text { Площадь, } \\
\text { га }\end{array}$ \\
\hline 52 & $14,15,17,18$ & 2,3 & 37 & $9,17,19,30$ & 2,1 \\
\hline 51 & $27,28,50$ & 5,3 & 35 & 14 & 0,5 \\
\hline 49 & $6,7,24,25,29,30$ & 20,6 & 33 & $8,10,11,17,20,35,39$ & 2,3 \\
\hline 47 & 5,10 & 1,5 & 31 & $10,11,13,20,22$ & 2,0 \\
\hline 45 & $5,7,17,25,27,28$ & 14,9 & 29 & 16,25 & 0,7 \\
\hline 43 & $11,13,14,15,26,34$ & 11,3 & 27 & $13,20,27$ & 1,9 \\
\hline 41 & 12,35 & 2,9 & 25 & 21,24 & 72,8 га \\
\hline 39 & $11,16,32,33,35$ & 3,0 & & \\
\hline
\end{tabular}

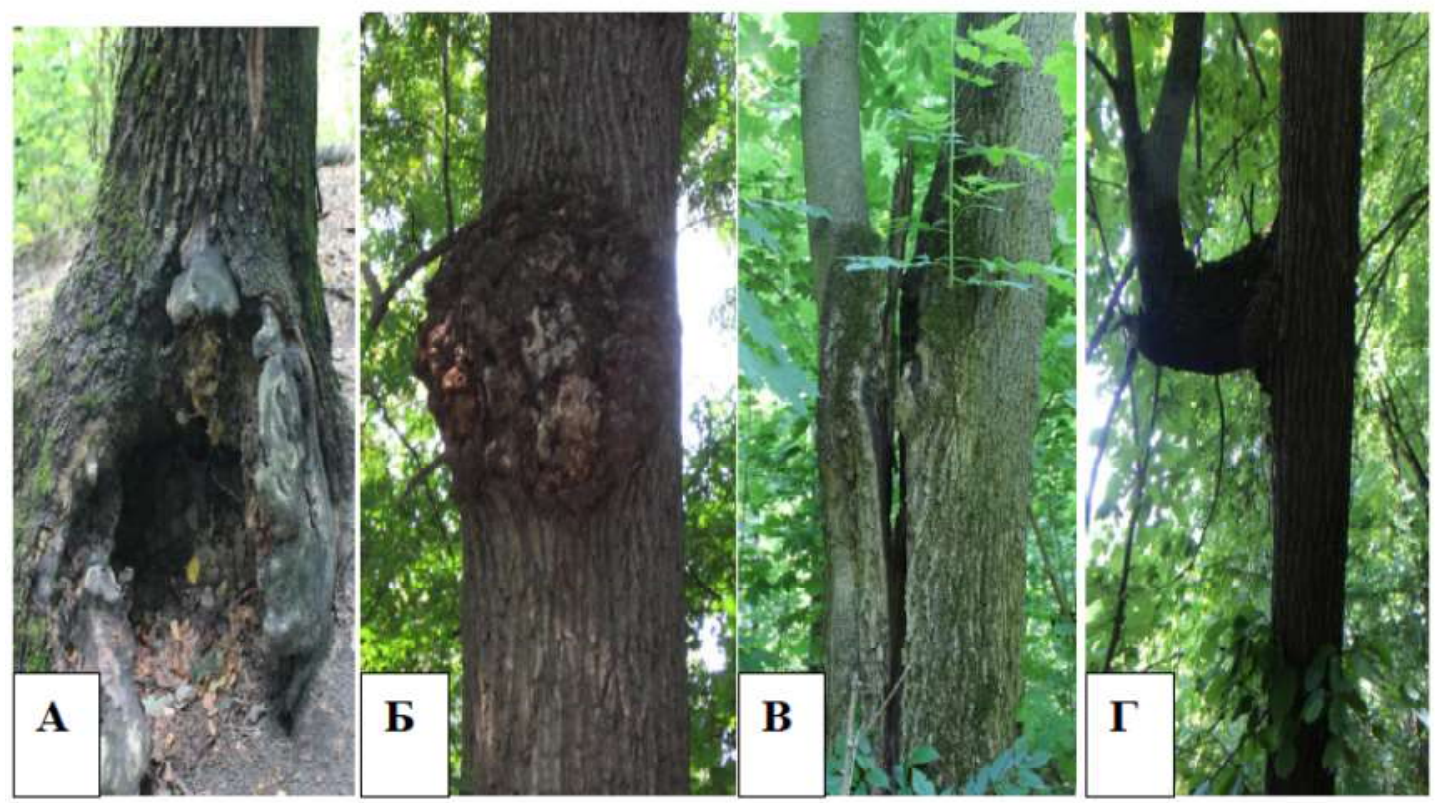

Рис. 1. Фатальные патологии, не учитываемые при определении аварийных деревьев:

а) большое комлевое дупло; б) раковая опухоль; в) расщепление ствола; г) толстые скелетные ветви (фото В.В. Царалунга) 
Таблица 2

Распределение аварийных деревьев по породам

\begin{tabular}{|c|c|c|c|c|c|}
\hline Порода & $\begin{array}{c}\text { Количество, } \\
\text { шт. / \% }\end{array}$ & $\begin{array}{c}\text { Общий запас, } \\
\mathrm{m}^{3} / \%\end{array}$ & Порода & $\begin{array}{c}\text { Количество, } \\
\text { шт. / \% }\end{array}$ & $\begin{array}{c}\text { Общий запас, } \\
\mathbf{m}^{3} / \%\end{array}$ \\
\hline Дуб & $243 / 62,9$ & $140,67 / 65,9$ & Ольха & $9 / 2,3$ & $5,88 / 2,8$ \\
\hline Ясень & $39 / 10,1$ & $27,33 / 12,7$ & Береза & $6 / 1,5$ & $5,77 / 2,7$ \\
\hline Клён & $31 / 8,1$ & $10,83 / 5,1$ & Груша & $1 / 0,3$ & $1,10 / 0,5$ \\
\hline Липа & $30 / 7,8$ & $7,24 / 3,4$ & Ива & $1 / 0,3$ & $0,19 / 0,1$ \\
\hline Осина & $26 / 6,7$ & $14,46 / 6,8$ & Итого: & $\mathbf{3 8 6 / 1 0 0 \%}$ & $\mathbf{2 1 3 , 4 8 / 1 0 0 , 0 \%}$ \\
\hline
\end{tabular}

*собственные вычисления авторов

Таблица 3

Распределение деревьев по признакам аварийности

\begin{tabular}{|c|c|c|c|c|c|}
\hline Порода & $\begin{array}{c}\text { Гниль, } \\
\text { шт. / \% }\end{array}$ & $\begin{array}{c}\text { Наклон, } \\
\mathrm{m}^{3} / \%\end{array}$ & Порода & $\begin{array}{c}\text { Гниль, } \\
\text { шт. } / \%\end{array}$ & $\begin{array}{c}\text { Наклон, } \\
\mathrm{m}^{3} / \%\end{array}$ \\
\hline Дуб & $198 / 51,3$ & $45 / 11,7$ & Ольха & $8 / 2,1$ & $1 / 0,3$ \\
\hline Ясень & $32 / 8,3$ & $7 / 1,8$ & Береза & $6 / 1,5$ & - \\
\hline Клён & $15 / 3,9$ & $16 / 4,1$ & Груша & $1 / 0,3$ & - \\
\hline Липа & $9 / 2,3$ & $21 / 5,4$ & Ива & $1 / 0,3$ & - \\
\hline Осина & $23 / 5,9$ & $3 / 0,8$ & Итого: & \multicolumn{2}{|c|}{$\mathbf{3 8 6 / 1 0 0 , 0 \%}$} \\
\hline
\end{tabular}

*собственные вычисления авторов

Всего было выявлено 386 аварийных деревьев с явной стволовой гнилью (плодовые тела дереворазрушающих грибов, большие выгнившие дупла на стволе) или сильным наклоном (более $30^{\circ}$ ) в сторону «тропы». Подавляющее большинство аварийных деревьев, и по количеству (62,9 \%), и по запасу (65,9 \%), приходится на деревья дуба черешчатого (табл. 2), притом, что он составляет порядка $50 \%$ древостоя по обоим этим показателям.

Среди остальных пород аварийные деревья встречались практически в таких же пропорциях, в каких встречаются порода в обследуемом насаждении.

От общего количества деревьев, расположенных вдоль тропы, аварийными признаны только 1,44\%. Такой относительно небольшой процент обнаруженных аварийных деревьев обусловлен тем, что Правобережное участковое лесничество находится в зеленой зоне города Воронежа и в нем регулярно проводятся выборочные санитарные рубки, при которых удаляется накопившейся бурелом, ветровал и сухостой.

Лесотехнический журнал $3 / 2020$
По признакам аварийности на всех породах преобладает стволовая гниль, к которой были приравнены все сухостойные деревья (табл. 3).

Деревья сухостойные или с хорошо развитой стволовой гнилью составили в сумме 75,9 \% против доли зависших ветровальных деревьев или имеющих сильный наклон или изгиб в сторону тропы в $24,1 \%$.

Но, как было отмечено выше, кроме перечисленных патологий у отечественных древесных пород встречаются аномалии развития, повреждения и заболевания, которые также делают нахождение рядом с ними опасным.

В табл. 4 приводятся данные о встречаемости некоторых из них в обследованных насаждениях. С большим отрывом среди выбранных дополнительных признаков лидируют комлевые дупла (77,6 \%). Обусловлено это спецификой насаждения, в котором преобладают деревья дуба черешчатого порослевого происхождения. Практически все такие деревья имеют в той или иной степени развитую комлевую гниль, не всегда выраженную в виде 


\section{Природопользование}

комлевого дупла. Но если пришлось бы учитывать все деревья с комлевыми дуплами на исследуемой территории, а не только угрожающие вывалом в сторону тропы, то таких бы деревьев оказалось на порядок больше.

На втором месте среди этой группы признаков оказалось расщепление ствола $(9,6 \%)$. Как и в случае с комлевыми дуплами, если учитывать все деревья с опасным раздвоением ствола, а не только уже имеющие трещины, как мы это делали, то таких деревьев тоже окажется гораздо больше.

Несколько меньше было отмечено деревьев с большими раковыми опухолями (8,8 \%). Однако это вполне существенная цифра, если учитывать, что такая патология практически всегда ведет к фатальному снижению механических свойств древесины в месте расположения опухоли и к неизбежному облому ствола.

Меньше всего было отмечено деревьев с толстыми скелетными ветвями, усохшими полностью или частично и нависающими над тропой (4 \%). Тем не менее, исходя из практического опыта, нам известно, что захламление лесных комму- никаций обломками крупных ветвей соизмеримо по объему с образующимся валежом.

В сумме дополнительные патологические признаки составили 62,4 \% от официально зарегистрированных. Это свидетельствует о том, что перечисленные патологические признаки имеют достаточно большое распространение и оставление деревьев с такими патологиями вдоль лесных коммуникаций представляет для них реальную угрозу.

При сравнительном анализе «штатных» признаков и дополнительных (рис. 2) видно, что последние по отдельности уступают первым (кроме комлевого дупла), но в сумме вполне соизмеримы и, несомненно, требуют учета.

Следует также отметить, что есть еще ряд существенных патологий, которые увеличивают риск вывала дерева или облома его ствола, но которые мы не учитывали, поскольку в данном конкретном насаждении они не были представлены или встречались единично в местах, не угрожающих обследуемой тропе. Но они в существенном количестве могут встречаться в других типах лесных насаждений.

Таблица 4

Распределение дополнительных патологических признаков

\begin{tabular}{|c|c|c|c|c|c|}
\hline Порода & $\begin{array}{c}\text { Комлевое } \\
\text { дупло, } \\
\text { шт. / \% }\end{array}$ & $\begin{array}{c}\text { Раковая опу- } \\
\text { холь, } \\
\text { шт. } / \%\end{array}$ & $\begin{array}{c}\text { Расщепление } \\
\text { ствола, } \\
\text { шт. } / \%\end{array}$ & $\begin{array}{c}\text { Толстые ске- } \\
\text { летные ветви, } \\
\text { шт. / \% }\end{array}$ & $\begin{array}{c}\text { Итого, } \\
\text { шт. / \% }\end{array}$ \\
\hline Дуб & $141 / 58,6$ & $9 / 3,9$ & $11 / 4,7$ & $3 / 1,2$ & $164 / 68,0$ \\
\hline Ясень & $17 / 7,1$ & $1 / 0,4$ & $3 / 1,2$ & $1 / 0,4$ & $22 / 9,1$ \\
\hline Клён & $4 / 1,7$ & - & $1 / 0,4$ & - & $5 / 2,1$ \\
\hline Липа & $1 / 0,4$ & - & $4 / 1,7$ & $1 / 0,4$ & $6 / 2,5$ \\
\hline Осина & $12 / 4,9$ & - & $1 / 0,4$ & $3 / 1,2$ & $16 / 6,6$ \\
\hline Вяз & $3 / 1,2$ & $7 / 2,9$ & $2 / 0,8$ & - & $2 / 4,9$ \\
\hline Ольха & $1 / 0,4$ & $1 / 0,4$ & - & - & $8 / 0,8$ \\
\hline Береза & $2 / 0,8$ & $3 / 1,2$ & $1 / 0,4$ & - & 5,3 \\
\hline Груша & $5 / 2,1$ & - & - & - & $1 / 2,1$ \\
\hline Ива & $1 / 0,4$ & - & $21 / 9,6$ & $10 / 4,0$ & $241 / 100,0$ \\
\hline Всего & $187 / 77,6$ & $21 / 8,8$ & & & 2,4 \\
\hline
\end{tabular}

\footnotetext{
* собственные вычисления авторов
} 


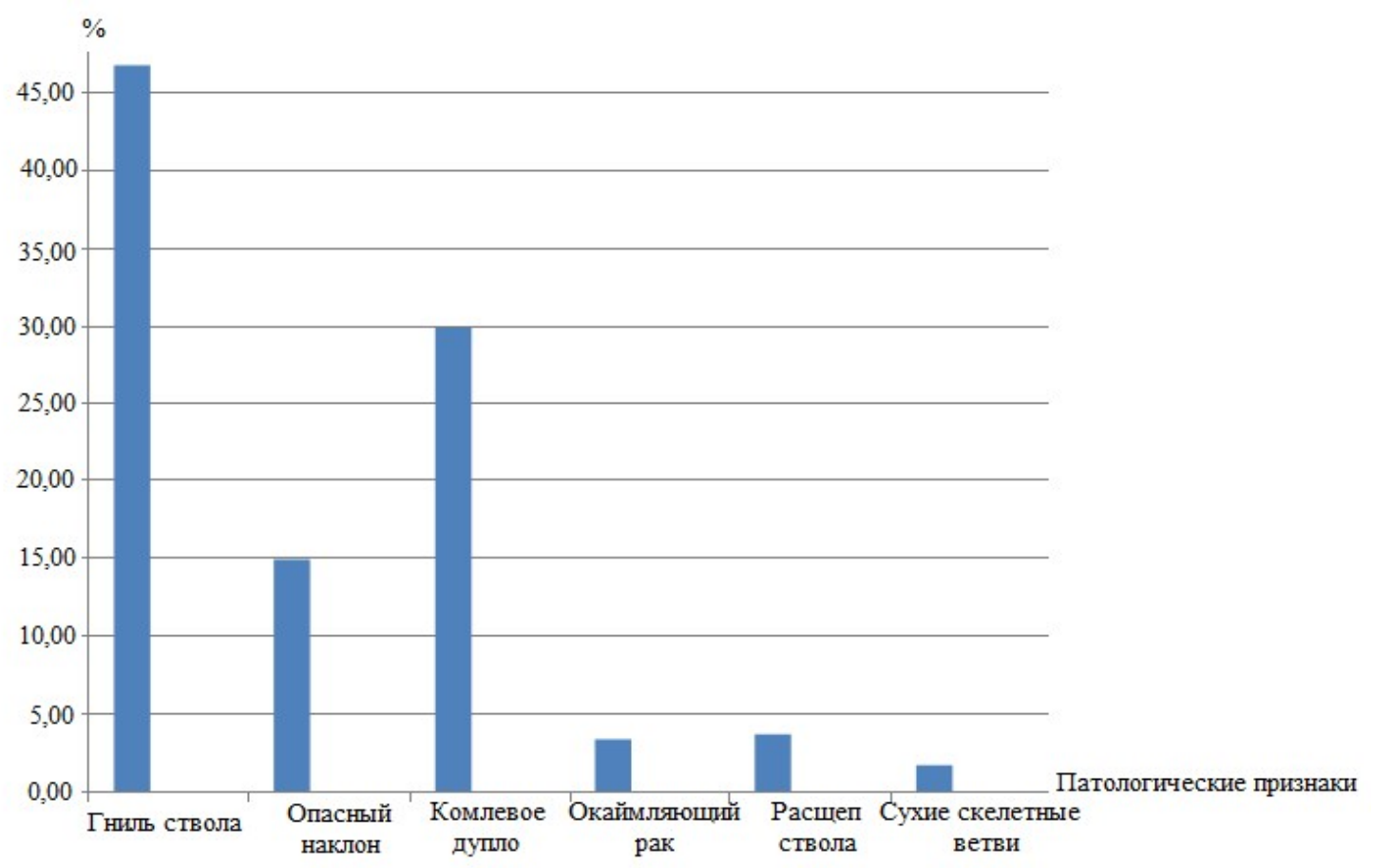

Рис. 2. Соотношение «штатных» и дополнительных патологических признаков в нагорной порослевой дубраве Правобережного участкового лесничества вдоль экологической тропы (собственные вычисления авторов)

Это не заросшие морозобойные и грозобойные трещины (рис. 3, а), большие каллусные напльвы, под которыми образуется гниль (рис. 3, б), срастание стволов, которое в обязательном порядке, рано или поздно, ведет к образованию гнили в месте срастания (рис. 3 , в), и значительное оголение корней за счет вымывания и выветривания грунта, которое провоцирует вывал дерева (рис. 3, г).

Поскольку исследования проводились исключительно в однотипных насаждениях (нагорная порослевая дубрава с приспевающим и спелым древостоем), то закономерно, что в других типах насаждений могут преобладать другие фатальные патологические признаки $[2,10]$. Так, в сосновых насаждениях опасными с позиций аварийности могут быть сырорастущие деревья, находящиеся на периферии очага корневой губки (Heterobasidion annosum) или существенно пострадавшие от низового пожара. А, к примеру, в березняках, осинниках и ольшаниках представляет аварийную опасность любое перестойное дерево, даже если оно не имеет внешних признаков, поскольку при экстремальных погодных условиях у таких деревьев большая вероятность буре-снеголома и ветро-снеговала.

\section{Выводы}

В результате проведенных исследований можно констатировать, что современная методика выделения аварийных деревьев в насаждениях гослесфонда несовершенна, поскольку не учитывает значительное количество древесных патологий, которые увеличивают вероятность облома или вывала дерева, чем однозначно делают такие деревья аварийно опасными. Исходя из этого, целесообразно внести в перечень аварийных деревья с развитой стволовой гнилью, опасным наклоном, обширным комлевым дуплом, окаймляющей раковой опухолью, расщепом раздвоенного ствола и усохшими скелетными ветвями. 


\section{Природопользование}
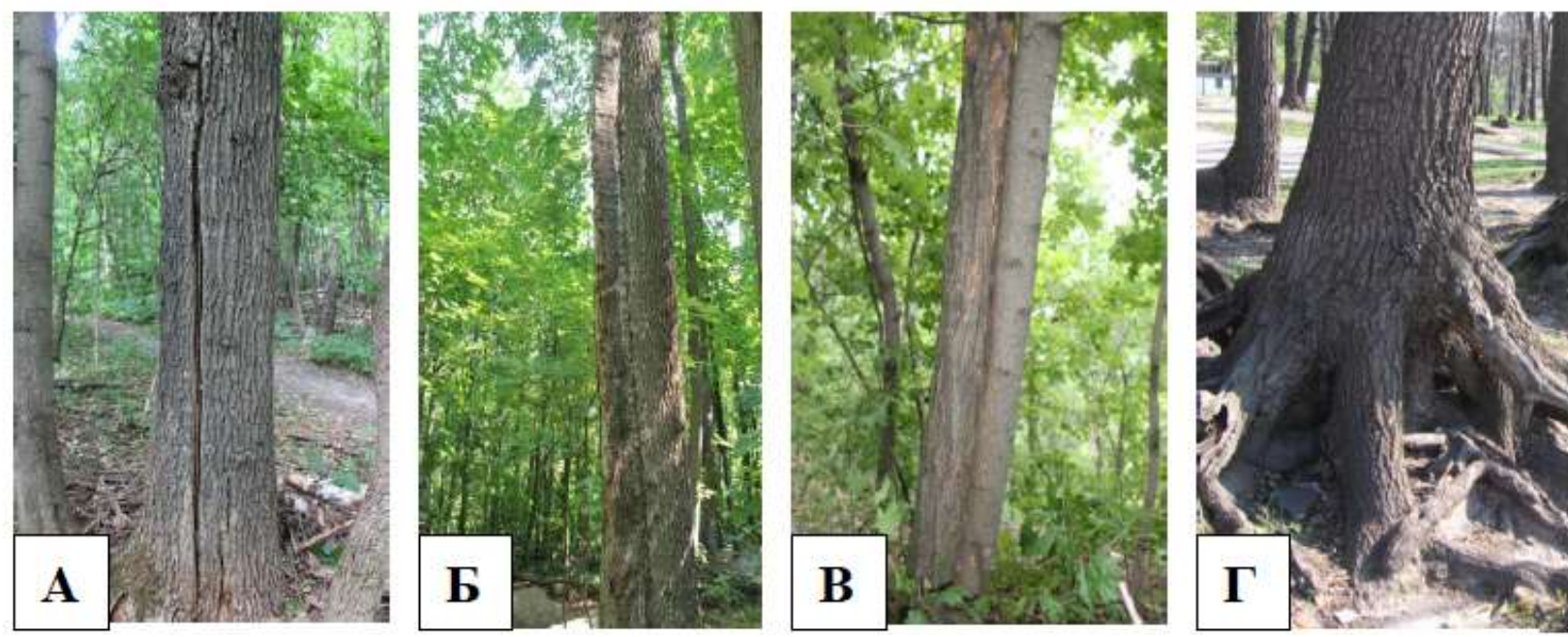

Рис. 3. Фатальные патологии, не учитываемые при определении аварийных деревьев и не фиксированные при наших исследованиях: а) не заросшие, крупные морозобойные и грозобойные трещины; б) большие каллусные наплывы на месте трещин или механических травм; в) сросшиеся стволы; г) оголенные корни (фото В.В. Царалунга)

\section{Библиографический список}

1. Аносов, Е. А. Аварийные деревья зеленых насаждений городов. Методы визуальной и инструментальной диагностики / Е. А. Аносов ; М-во образования и науки РФ, ФГБОУ ВО «Тихоокеанский государственный университет». - Хабаровск, 2015. - 117 с. - Библиогр.: с. 116-117.

2. Ерзин, И. В. Оценка состояния насаждений городских парков в связи с их реконструкцией: на примере г. Москвы: специальность 03.02.08 «Экология» : автореф. дис. ... канд. биол. наук : защищена 17.11.2011 / Ерзин Иван Васильевич ; ГОУ ВПО «МГУЛ». - Москва, 2011. - 19 с.

3. Приказ Госстроя Российской Федерации от 15.12.1999 № 153 «Об утверждении Правил создания, охраны и содержания зеленых насаждений в городах Российской Федерации». - URL: http://www.consultant.ru/document/cons_doc_LAW_98762 (дата обращения: 11.05.2020).

4. Федеральный закон от 06.10.2003 № 131-Ф3 «Об общих принципах организации местного самоуправления в Российской Федерации». - URL: http://www.consultant.ru/document/cons_doc_LAW_44571 (дата обращения: 11.05.2020).

5. Houston, D. R. Dieback and declines of urban trees / D. R. Houston // Journal of Arboriculture. - 1985. Vol. 11 (3). - P. 65-72.

6. Постановление Правительства Российской Федерации от 20.05.2017 № 607 «О Правилах санитарной безопасности в лесах». - URL: https://base.garant.ru/71685642 (дата обращения: 20.07.2020).

7. Приложение 1 к приказу Рослесхоза от 20.05.2017 № 607 «Руководство по проектированию, организации и ведению лесопатологического обследования» : утв. Рослесхозом, 2017. - 73 с.

8. Воронцов, А. И. Патология леса : моногр. / А. И. Воронцов. - Москва : Лесн. пром-сть, 1978. - 272 с. Библиогр.: с. 251-266.

9. Boyce, J. S. Forest Pathology / J. S. Boyce ; 3 ed. - New York, 1961. - 572 p.

10. Царалунга, В. В. Внешние признаки патологии дуба черешчатого : моногр. / В. В. Царалунга, Е. С. Фурменкова, А. А. Крюкова. - Воронеж, 2015. - 231 с. - ISBN 978-5-7994-0712-4. - URL: https://znanium.com/catalog/product/858234 (дата обращения: 22.07.2020). - Режим доступа: по подписке.

11. Blanco, J. A. Forest Ecosystems - More than Just Trees / J. A. Blanco, Yueh-Hsin Lo. - Rijeka, Croatia, 2012. - 480 p. - ISBN 978-953-51-0202-1. 
12. Korchagin, O. M. Oak forest bioconoses: overview of the issue of their environmental sustainability and possible ways to enhance it / O. M. Korchagin, V. V. Tsaralunga, A.V. Tsaralunga // International Journal of Advanced Biotechnology and Research WoS. - 2018. - Vol. 9 (4). - P. 397-402.

13. Tsaralunga, V. V. Improvement of tree condition diagnostics by external pathology characteristics / V. V. Tsaralunga, A. V. Tsaralunga, E. S. Furmenkova // IOP Conference Series: Earth and Environmental Science, 2019. - Vol. 226. - P. 012069. - DOI: 10.1088/1755-1315/226/1/012069.

\section{References}

1. Anosov E.A. Avariynye derev'ya zelenykh nasazhdeniy gorodov. Metody vizual'noyi instrumental'noy diagnostiki [Emergency trees of green spaces of cities. Methods of visual and instrumental diagnostics]. Khabarovsk, 2015. 117 p. (in Russian).

2. Erzin I.V. Otsenka sostoyaniya nasazhdeniy gorodskikh parkov v svyazi s ikh rekonstruktsiey: na primere g. Moskvy: avtoref. dis. ... kand. biol. nauk [Assessment of the state of urban Park stands in connection with their reconstruction: on the example of Moscow: $\mathrm{PhD}$ (Biology) thesis abstr.]. Moscow, 2011. 19 p. (in Russian).

3. Order Of Gosstroy Of The Russian Federation 15.12. 1999 № 153 «Ob utverzhdenii Pravil sozdaniya, okhrany $i$ soderzhaniya zelenykh nasazhdeniy v gorodakh Rossiyskoy Federatsii»» [About the approval of Rules of creation, protection and maintenance of green spaces in the cities of the Russian Federation]. URL: http://www.consultant.ru/document/cons_doc_LAW_98762 (in Russian).

4. Federal law 06.10.2003 № 131-FZ «Ob obshchikh printsipakh organizatsii mestnogo samoupravleniya $v$ Rossiyskoy Federatsii» [About the General principles of the organization of local self-government in the Russian Federation]. URL: http://www.consultant.ru/document/cons_doc_LAW_44571 (date of access 11 May 2020) (in Russian).

5. Houston D.R. (1985) Dieback and declines of urban trees. Journal of Arboriculture, Vol. 11 (3), pp. 65-72.

6. Resolution of the Government of the Russian Federation of 20.05.2017 N 607 "O Pravilakh sanitarnoy bezopasnosti v lesakh" [On rules of sanitary safety-news in forests]. URL: https://base.garant.ru/71685642/ (date of access 11 May 2020) (in Russian).

7. Prilozhenie 1 k prikazu Rosleskhoza ot 20.05.2017, № 607 «Rukovodstvo po proektirovaniyu, organizatsii $i$ vedeniyu lesopatologicheskogo obsledovaniya» [Guidelines for the design, organization and management of forest pathology surveys], 2017. 73 p. (in Russian).

8. Vorontsov A.I. Patologiya lesa [Forest pathology]. Moscow, 1978. 272 p. (in Russian).

9. Boyce J.S. Forest Pathology ; 3 ed. New York, 1961. 572 p.

10. Tsaralunga V.V., Furmenkova E.S., Kryukova A.A. Vneshnie priznaki patologii duba chereshchatogo [External signs of pathology of oak petiolate]. Voronezh, 2015. 231 p. (in Russian). ISBN 978-5-7994-0712-4.

11. Blanco J.A., Yueh-Hsin Lo. Forest Ecosystems - More than Just Trees. Rijeka, Croatia, 2012. 480 p. ISBN 978-953-51-0202-1.

12. Korchagin O.M., Tsaralunga V.V., Tsaralunga A.V. (2018) Oak forest bioconoses: overview of the issue of their environmental sustainability and possible ways to enhance it. International journal of Advanced biotechnology and research WoS, Vol. 9 (4), pp. 397-402.

13. Tzaralunga V.V., Tzaralunga A.V., Furmenkova E.S. Improvement of tree condition diagnostics by external pathology characteristics. IOP Conference Series: Earth and Environmental Science, 2019. Vol. 226 : 012069. DOI: $10.1088 / 1755-1315 / 226 / 1 / 012069$. 


\section{Сведения об авторах}

Царалунга Владимир Владимирович - доктор сельскохозяйственных наук, профессор кафедры экологии, защиты леса и лесного охотоведения ФГБОУ ВО «Воронежский государственный лесотехнический университет имени Г.Ф. Морозова», г. Воронеж, Российская Федерация; e-mail: caralunga@bk.ru.

Царалунга Анна Викторовна - кандидат биологических наук, доцент кафедры экологии, защиты леса и лесного охотоведения ФГБОУ ВО «Воронежский государственный лесотехнический университет имени Г.Ф. Морозова», г. Воронеж, Российская Федерация; e-mail: saralunga@yandex.ru.

Короткая Анна Владимировна - магистрант кафедры экологии, защиты леса и лесного охотоведения, ФГБОУ ВО «Воронежский государственный лесотехнический университет имени Г.Ф. Морозова», г. Воронеж, Российская Федерация; е-mail:kor9096@mail.ru.

\section{Information about authors}

Tsaralunga Vladimir Vladimirovich - DSc (Agriculture), Associate Professor, Professor of the Department of Ecology, Protection of Forests and Forest-Hunt Conduction, FSBEI HE «Voronezh State University of Forestry and Technologies named after G.F. Morozov», Voronezh, Russian Federation; e-mail: caralunga@bk.ru.

Tsaralunga Anna Viktorovna - PhD (Biology), Associate Professor of the Department of Ecology, Protection of Forests and Forest-hunt conduction, FSBEI HE "Voronezh State University of Forestry and Technologies named after G.F. Morozov", Voronezh, Russian Federation; e-mail: saralunga@yandex.ru.

Korotkaya Anna Vladimirovna - Master's degree student of the Department of Ecology, Protection of Forests and Forest-hunt conduction, FSBEI HE "Voronezh State University of Forestry and Technologies named after G.F. Morozov", Voronezh, Russian Federation; e-mail: kor9096@mail.ru. 